\title{
QUU
}

\section{DETERMINAÇÃO DO TEOR DE NITRATO E POTABILIDADE NA ÁGUA DE RESERVATÓRIOS E AFLUENTES DA BARRAGEM ENGENHEIRO ARMANDO RIBEIRO GONÇALVES, RIO AÇU E AÇUDE DE PATAXÓ.}

${ }^{*}$ F. J. Buriti ${ }^{1}$ (IFRN); Y. Y. M. B. da Silva ${ }^{2}$ (IFRN); I. Marshal ${ }^{3}$ (IFRN); O. S.Maciel ${ }^{4}$ (IFRN); D. P. Bezerra ${ }^{5}$ (IFRN). E-mails: janikellyburiti@hotmail.com ${ }^{1}$; Italo.marshal@hotmail.com ${ }^{2}$; york_yury@hotmail.com ${ }^{3}$; ozanira_soares@hotmail.com ${ }^{4}$; diogo.bezerra@ifrn.edu.br ${ }^{5}$.

Palavras Chave: Nitrato, Análises, Água, Qualidade.

\section{INTRODUÇÃO}

Sabemos que a água e de grande abundância na terra, cerca de $97 \%$ água salgada e apenas $3 \%$ potável. O nitrato é o poluente de ocorrência mais freqüente nas águas subterrâneas (HIRATA, VARNIER, 2002). O nitrogênio é um dos elementos mais importante para o metabolismo da vida aquática.

É de suma importância às análises da água para que estejamos consumindo uma água potável de ótima qualidade seguindo os parâmetro determinados pela lei 9.433 de 8 de maio de 1997.

\section{METODOLOGIA}

As análises seguiram a metodologia de FERREIRA, 2012.

- Coleta
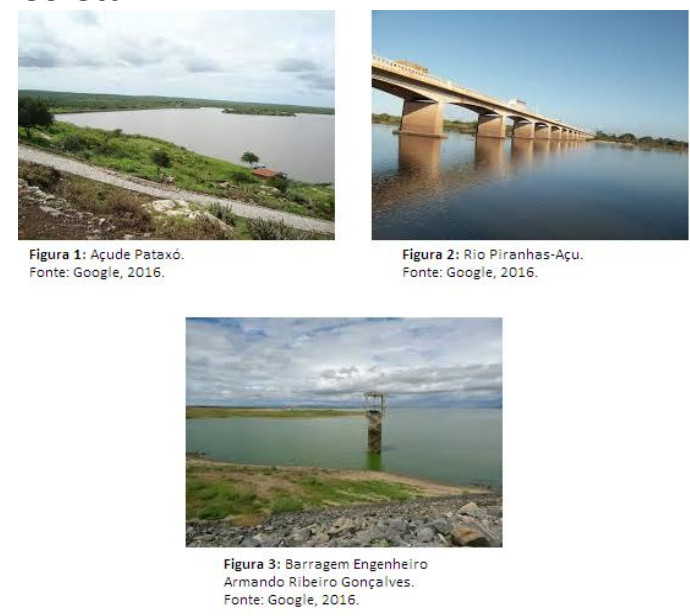

- Filtragem

\section{RESULTADOS E DISCUSSÕES}

Os valores obtidos das amostras estão enquadrados no índice de qualidade de água estabelecido pelo Ministério da Agricultura, Pecuário e Abastecimento, portaria no 2914, de 12 de dezembro de 2011, em 1 VPM $^{(2)}$.

Tabela 2: Resultados das análises

\begin{tabular}{|c|c|}
\hline Reservatório & VPM $^{(2)}$ \\
\hline $\begin{array}{c}\text { Barragem E. A. R. } \\
\text { Gonçalves }\end{array}$ & 0,191 \\
\hline Rio Piranhas Açu & 0,116 \\
\hline Açude de Pataxó & 0,2 \\
\hline
\end{tabular}

Fonte: BURITI, 2016.

Para tanto, podemos ver que as amostras analisadas obtiveram padrões considerados bons, para o consumo das águas dos reservatórios estudados.

\section{CONCLUSÃO}

Ao término do trabalho, foi possível constatar que os reservatórios analisados, possuem águas que podem ser consumida, pois possuem níveis de nitratos considerados normais para consumo.

\section{REFERÊNCIAS}

BRASIL. Ministério da Agricultura, Pecuário e Abastecimento, 2011.

BRASIL. Da Política Nacional De Recursos Hídricos, 1997.

Hirata, R; Varnier, C. Contaminação Da Água Subterrânea Por Nitrato No Parque Ecologico Do Tietê - São Paulo, 2002. 